\title{
Incidence of depression and the coping styles used for it by under graduate and post graduate pharmacystudents: a comparison
}

\begin{abstract}
Depression is one of the most prevalent mental conditions worldwide affecting the general population. Students are presumably prone to this condition because of academic and personal stressors. Depressed students employ a variety of coping methods to deal with their condition. A prospective study was conducted by stratified random sampling in which questionnaire was distributed randomly to 196 undergraduate and postgraduate pharmacy students out of 401 registered students of the pharmacy department of the institution. The study estimated the incidence of depression using CES-D scale and determined different coping styles used by depressed university scholars with the help of 28-item Brief Cope inventory. Various academic and personal stressors were also identified. Overall, (118) $60 \%$ university scholars were depressed. Female students were more depressed than male students. Assignments, frequent examination and quizzes were the major stressors for the students. Religion and substance use were the most and least commonly used coping methods for depression, respectively. Measures should be taken by the institution to routinely assess the mental health status of students and health promotional programs should be initiated for improving the personal and professional life of university scholars.
\end{abstract}

Keywords: Depression, Coping styles, Stressors, Pharmacy students, Counseling, Pakistan
Volume 5 Issue 2 - 2017

\author{
Saliha Khalid,' Annum Bukhari,' Saira Azhar,' \\ Nidda Saeed,' Sohail Manzoor, ${ }^{3}$ Humaira \\ Syed,' Fraz Munir Khan, ${ }^{3}$ Akash Syed,' Syed \\ Abbas Ali, ${ }^{4}$ Muhammad Ali, ${ }^{2}$ Muhammad \\ Saleem Kamboh ${ }^{5}$ \\ 'Department of Pharmacy, COMSATS, Pakistan \\ 2Faculty of Pharmacy, University of Punjab, Pakistan \\ ${ }^{3}$ Disease Diagnostic Laboratories, L\&DD, Pakistan \\ Provincial Diagnostic Laboratory, L\&DD, Pakistan \\ ${ }^{5}$ Directorate General (Research), L\&DD, Pakistan
}

Correspondence: Saliha Khalid, Department of Pharmacy, COMSATS, Abbottabad, Pakistan, Tel +923336503982:

Email manzoorsohaij76@gmail.com

Received: January 28, 2017| Published: March 07, 2017

\section{Introduction}

Depression is prevalent worldwide and estimated to be the third most common cause of disabling conditions and expected to be the leading cause of disability by the year $2030 .{ }^{1}$ Depressive disorders were associated with the second most common cause of years lived with disability (YLDs) in 2010 and was identified to be the topmost contributing cause to disability adjusted life years (DALYs), without mortality as an underlying cause. According to findings of the study on Global Burden of Disease (GBD) 2010, depression was identified as the leading cause contributing to the health burden..$^{2-4}$ A systematic review reveals the prevalence of anxiety and depression in Pakistani population to be around $34 \% .5$ Depression is one of the frequent health ailments affecting the university scholars. ${ }^{6}$ University scholars are at a higher risk of depression, and according to a systematic review of studies focused on the prevalence of depression published between 1990-2010, an estimated mean prevalence of $30.6 \%$ was identified which suggests that the incidence of depression is higher in university scholars as compared to the general population. ${ }^{7}$ It has also resulted in poor academic performance of university scholars. ${ }^{8}$ Incidence of depression may also predispose the students to different other health disorders like HIV infection, diabetes and increased risk of suicidal tendency. ${ }^{9-11}$ The common stressors identified include academic stressors, social stresses and financial problems. ${ }^{12}$ Coping Strategies refer to different continuous psychological, behavioral and emotional processes to deal with different stressors. ${ }^{13}$

While depression in certain age groups such as adolescents or the elderly has contributed to rising apprehension. ${ }^{14-18 .}$ In spite of the evidence suggesting that there has been a gradual increase in the number of depressed university scholars, the problem has not been served with due attention. ${ }^{19}$ Regardless of such pernicious effects of depression, there have been limited studies conducted in Higher
Education Institutions of Pakistan to confront mental health problems. Stress is a part of life and not just a part of university life. If the problem of depression is not managed appropriately, it will result in various physical emotional and interpersonal problems. Therefore, it is an important skill of life to learn how to deal and manage with depression by keeping a positive approach.

\section{Methods}

\section{Study design}

A questionnaire was designed from two standard questionnaires for checking the incidence of depression and the coping styles used by students to tackle their depression. The questionnaire had four parts including basic socio-demographic information, CES-D scale, various stressors and 28-item Brief Cope Inventory.

CES-D scale: It is a short self-report depression scale to measure the depression symptoms of population. It consisted of 10 questions. The score range was $0-30$. Individuals with score greater than 10 were considered to be depressed.

Stressors: Most common sources of stress for university scholars were included in the questionnaire categorized into two types; academic stressors involving frequent examinations, quizzes and assignments whereas personal stressors included class competition, lack of sleep, interpersonal relationship problems, personal or family health issues, death of a loved one and financial issues.

Brief Cope-28: It is the short version of original COPE Inventory and evaluates 14 coping styles and there were 2 questions per coping style. The answers to the questions were evaluated using a 4-point likert scale with responses varying from 1(I have not been doing this at all) to 4 (I have been doing this a lot). The scores vary from 2 to 8 . 


\section{Sample size}

Total sample size was selected to be 196 from the total 401 registered students of the pharmacy department of the institution in the year 2016. Samples were collected by stratified random sampling.

\section{Data collection Procedure}

Every selected student was detailed about the study objectives and oral consent was taken of each student for inclusion in the study. Questionnaires were distributed to the randomly selected registered pharmacy students of COMSATS Abbottabad and were filled by the students. Data was collected prospectively from all the respondents.

\section{Data Analysis}

Data was statistically analyzed by Statistical Package for Social Sciences (SPSS, version 20). Descriptive statistics were performed and results were mentioned in the form of percentage and frequency. The Chi-square test was used to test the significance of association between the dependent variable of incidence of depression and various independent variables (frequent examinations, quizzes, assignments, class competition, and lack of sleep, interpersonal relationship problems, personal or family health issues, financial issues, social activities and colleagues support). The $\mathrm{P}$ value of $<0.05$ was considered statistically significant. Mean of each coping style was calculated to determine the frequency of their use by depressed students.

\section{Results}

\section{Basic sociodemographic characteristics and incidence of depression}

Incidence of depression and the various coping styles used for it were determined from data collected from undergraduate and postgraduate pharmacy students. Social and demographic data of all students along with total number of depressed cases in each category is mentioned in Table 1-3. As a whole, $118(60 \%)$ students were depressed according to CES-D scale. And depression was more common in females $73(64 \%)$ as compared to males. And individuals with age less than 25 years were found to be more depressed.

Table I Student's socio-demographic data with percentage and frequency of depressed cases

\begin{tabular}{|c|c|c|}
\hline $\begin{array}{l}\text { No. Characteristics } \\
\text { Sex }\end{array}$ & n (\%) & Number of Depressed Cases (\%) \\
\hline Females & II4(58.2) & $73(64.0)$ \\
\hline Males & $82(41.8)$ & $45(54.9)$ \\
\hline \multicolumn{3}{|l|}{ Age } \\
\hline$<25$ Years & $145(74.0)$ & $91(62.8)$ \\
\hline$>25$ Years & $5 I(26.0)$ & $27(52.9)$ \\
\hline \multicolumn{3}{|l|}{ Educational Status } \\
\hline Pharm-D & $\mid 40(7 \mid .4)$ & $87(62.1)$ \\
\hline MS/PhD & $56(28.6)$ & $3 I(55.4)$ \\
\hline \multicolumn{3}{|c|}{ Pharmacy by own choice } \\
\hline Yes & $139(70.9)$ & $83(59.7)$ \\
\hline No & $57(29.1)$ & $35(6 I .4)$ \\
\hline \multicolumn{3}{|l|}{ Living Status } \\
\hline Day Scholar & $85(43.4)$ & $53(62.4)$ \\
\hline Boarder & III(56.6) & $65(58.6)$ \\
\hline \multicolumn{3}{|l|}{ Regular Exercise } \\
\hline Yes & $4 I(20.9)$ & $20(48.8)$ \\
\hline No & $155(79.1)$ & $98(63.2)$ \\
\hline \multicolumn{3}{|l|}{ Social Activities } \\
\hline Yes & $107(54.6)$ & $57(53.3)$ \\
\hline No & $89(45.4)$ & $61(68.5)$ \\
\hline \multicolumn{3}{|l|}{ Regular Meal } \\
\hline Yes & $138(70.4)$ & $80(58.0)$ \\
\hline No & $58(29.6)$ & $38(65.5)$ \\
\hline \multicolumn{3}{|l|}{ Colleagues Support } \\
\hline Yes & $147(75.0)$ & $81(55.1)$ \\
\hline No & $49(25.0)$ & $37(75.5)$ \\
\hline \multicolumn{3}{|l|}{ Supervisor Support } \\
\hline Yes & $122(62.2)$ & 68(55.7) \\
\hline No & $74(37.8)$ & $50(67.6)$ \\
\hline \multicolumn{3}{|l|}{ Sleeping Hours } \\
\hline$<8$ hours & $130(66.3)$ & $85(65.4)$ \\
\hline$>8$ hours & $66(33.7)$ & $33(50.0)$ \\
\hline \multicolumn{3}{|c|}{ Current Status of Postgraduates } \\
\hline Course Work & $20(35.7)$ & II (55.0) \\
\hline Research Work & $36(64.3)$ & $20(55.6)$ \\
\hline \multicolumn{3}{|c|}{ Professional Year of Pharm-D } \\
\hline IstYear & $25(17.9)$ & $16(64.0)$ \\
\hline 2nd Year & $29(20.7)$ & $20(69.0)$ \\
\hline 3rd Year & $33(23.6)$ & $20(69.0)$ \\
\hline 4th Year & $23(16.4)$ & 17(73.9) \\
\hline 5th Year & $30(21.4)$ & $14(46.7)$ \\
\hline
\end{tabular}


Table 2 Correlation between dependent variable (CES-D Scale Score) and various independent variables

\begin{tabular}{llll}
\hline Independent Variable & P value & Independent Variable & P value \\
\hline Frequent Examinations & 0.028 & Financial Issues & 0.025 \\
Assignments & 0.003 & Social Activities & 0.03 \\
Quizzes & 0.005 & Colleagues Support & 0.011 \\
Class competition & 0.144 & Loneliness or Isolation & 0.006 \\
Lack of Sleep & 0.15 & Sleeping hours & 0.038 \\
Interpersonal Relationship Problem & 0.101 & Personal or Family Health Issues & 0.019 \\
\hline
\end{tabular}

Table 3 Frequency and percentage of various coping styles and mean of coping styles score

\begin{tabular}{|c|c|c|c|c|c|}
\hline \multicolumn{6}{|l|}{$\mathbf{N}(\%)$} \\
\hline COPING STYLES & $\begin{array}{l}\text { I haven't been } \\
\text { doing this at all }\end{array}$ & $\begin{array}{l}\text { l've been doing } \\
\text { this a little bit }\end{array}$ & $\begin{array}{l}\text { I've been doing this a } \\
\text { medium amount }\end{array}$ & $\begin{array}{l}\text { I've been doing? } \\
\text { this a lot }\end{array}$ & $\begin{array}{l}\text { Means of coping style scores } \\
\text { in depressed students }\end{array}$ \\
\hline Active Coping & $5(4.2)$ & $20(16.9)$ & $67(56.8)$ & $20(22.1) \quad 5$ & 5.5 \\
\hline Instrumental Support & $9(7.6)$ & $40(33.9)$ & $50(42.4)$ & $19(16.1)$ & 4.92 \\
\hline Planning & $2(1.7)$ & $36(30.5)$ & $65(55.1)$ & $15(12.7)$ & 5.09 \\
\hline Acceptance & $6(5.1)$ & $25(2 \mid .2)$ & $63(53.4)$ & $24(20.4)$ & 5.36 \\
\hline Emotional Support & $9(7.6)$ & $57(48.3)$ & $42(35.6)$ & $10(8.4)$ & 4.43 \\
\hline Humor & $29(24.6)$ & $54(45.7)$ & $21(17.8)$ & I4 (I I.8) & 4.06 \\
\hline Positive Refraining & $4(3.4)$ & $45(38.1)$ & $49(41.5)$ & $20(17.0)$ & 4.99 \\
\hline \multirow{3}{*}{$\begin{array}{l}\text { Religion } \\
\text { Behavioral } \\
\text { Disengagement } \\
\text { Denial }\end{array}$} & I (0.8) & $19(16.1)$ & $4 \mathrm{I}(34.7)$ & $57(48.3)$ & 6.19 \\
\hline & $12(10.2)$ & $60(50.8)$ & $41(34.7)$ & $5(4.2)$ & 4.22 \\
\hline & $10(8.5)$ & $64(45.7)$ & $44(40.0)$ & $10(8.4)$ & 4.5 \\
\hline Self-Distraction & I (0.8) & $39(33.0)$ & $62(52.6)$ & $16(13.5)$ & 5.04 \\
\hline Self-Blame & $8(6.8)$ & $42(35.6)$ & $45(38.2)$ & $23(19.5)$ & 5.06 \\
\hline Substance Use & $95(80.5)$ & $19(16.1)$ & $3(2.5)$ & I (0.8) & 2.38 \\
\hline Venting & $9(7.6)$ & 40 (33.9) & $62(52.5)$ & $7(5.9)$ & 4.69 \\
\hline
\end{tabular}

\section{Stressors}

Various stressors including academic stressors and personal stressors are the cause of depression in university undergraduate and postgraduate students. Among the academic stressors, assignments (78\%) were the most prevalent cause of depression among students. Frequent examination (75\%) and quizzes $(71.4 \%)$ followed it. Lack of sleep was the most common personal stressor $(70 \%)$ for the students. Percentages of different stressors are depicted as a bar graph in Figure 1.

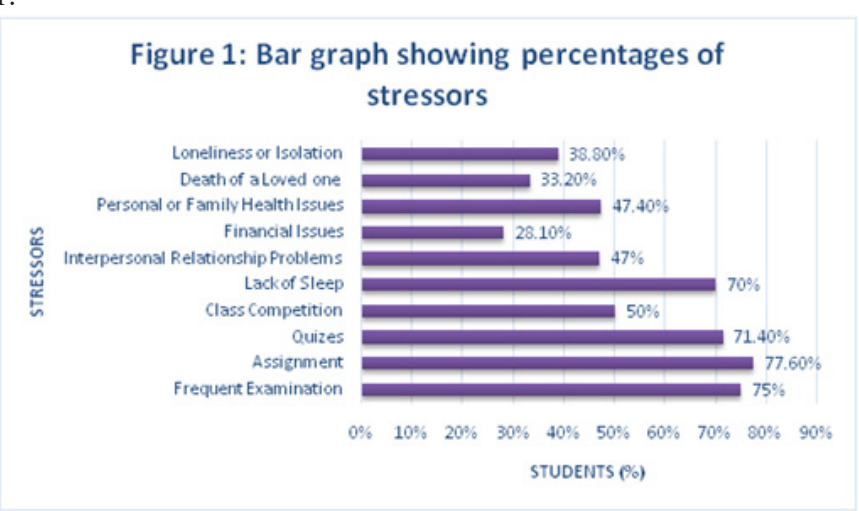

Figure I Bar graph showing percentages of stressors.

\section{Statistical significance of incidence of depression and various independent variables}

Frequent examination, assignments $(p=0.003)$ and quizzes significantly affected the incidence of depression and were also the most common academic stressors for the students. Lack of sleep and social activities were also significantly related to the depression scale. Loneliness, health issues and lack of colleagues support also had a statistically significant association with depression occurrence.

\section{Coping Styles}

Determination of different coping styles used by depressed scholars was done by using the standard 28 item brief COPE inventory tool. Various coping styles were used by students with religion being the most common style (mean=6.19). Whereas, substance use was the least commonly employed coping method (mean $=2.38$ ) by the depressed respondents. Active coping, acceptance and planning were other widely used styles.

\section{Discussion}

Depression is a frequent health related problem influencing the health of university scholars, affecting their studies and personal life. Studies from Thailand, India, Malaysia and Pakistan have identified stress in medical students and emphasized the role of academics as an important stressor. ${ }^{20-23}$ The aim of current study was to determine the incidence of depression, sources of stress for pharmacy students and different coping styles used by the depressed individuals. The study population focused on graduate and undergraduate pharmacy students. The study revealed that female students $(64 \%)$ were more depressed as compared to the male students. ${ }^{24}$ In this study, different sources of stress for the students were also measured. It was observed that students of age group less than 25 years were more depressed. This can be associated to assignments which being a major source of stress, followed by frequent examinations and quizzes. This academic stress may lead to anxiety. Many students marked more than 3 stressors in their life. There was significant association seen in sleeping hours $<$ $8(\mathrm{p}=0.038)$, colleague support $(\mathrm{p}=0.011)$ and students with no social activity $(\mathrm{p}=0.030)$ which contradicts the findings of another crosssectional study conducted on pharmacy students of Pakistan. Among less common stressors were class competition, financial issues and interpersonal relationship problems. ${ }^{24}$ 
Depression coping strategies are also involved in this study, and students have various coping styles for this purpose. Therefore, different responses to depression coping methods were observed. According to a significant proportion of depressed university scholars, they find comfort and relief in different religious practices. ${ }^{25}$ It is considered the easiest way to cope up with depression. Active coping and acceptance were the next most common coping methods. Whereas, substance use as a coping tool was least reported. "Use of alcohol or other drugs to feel better" can possibly account for the minimal score of this question. The other plausible reason may be that the collected data chiefly illustrates females, and men are presumably involved in substance abuse. Additionally, alcohol is a taboo for Muslims. Limitations of the study include need for identification of other factors causing stress to the students. Additionally, different coping styles employed by the depressed individuals must be evaluated for their effectiveness. Limited number of students and, lack of interventional procedures in terms of suggestions/counseling to the depressed respondents and follow up were the other limitations. So, a study should be conducted on a larger scale to evaluate the incidence of depression in the students of other departments for interdepartmental comparison.

Routine mental health assessment of the university students should be carried out by the institution. Practical implications should be made to help the depressed students. Students should be counselled about the use of positive coping styles by which they can tackle their problems effectively rather than moving towards the negative coping strategies such as humor, venting and self-blame. Students should also be provided with opportunities for co-curricular and social activities as according to the study findings, there was a significant association between incidence of depression and lack of social activities. These measures can ameliorate the academic performance of the students by improving the quality of their personal and professional life.

\section{Acknowledgments}

None.

\section{Conflicts of interest}

None.

\section{References}

1. Mathers C, Fat DM, Boerma JT The global burden of disease: 2004 update. World Health Organization. 2008

2. Ferrari AJ, Charlson FJ, Norman RE et al. Burden of depressive disorders by country, sex, age, and year: findings from the global burden of disease study 2010. 2013;10(11).

3. Murray CJ, Lopez AD Global burden of disease. Harvard University Press Boston, USA. 1996

4. Üstün T, et al. Global burden of depressive disorders in the year 2000. The British journal of psychiatry. 2004;184(5):386-392.

5. Mirza I, Jenkins R Risk factors, prevalence, and treatment of anxiety and depressive disorders in Pakistan: systematic review. Bmj. 2004;328(7443):794.

6. Lyubomirsky S, Kasri F, Zehm K Dysphoric rumination impairs concentration on academic tasks. Cognitive Therapy and Research. 2003;27(3):309-330.

7. Ibrahim AK, Kelly SJ, Adams CE et al. A systematic review of studies of depression prevalence in university students. $J$ psychiatr res. 2013;47(3):391-400.
8. Blackman GL, Ostrander R, Herman KC Children with ADHD and depression: A multisource, multimethod assessment of clinical, social, and academic functioning. J Atten Disord. 2005;8(4):195-207.

9. Garlow SJ, Rosenberg J, Moore JD et al. Depression, desperation, and suicidal ideation in college students: results from the American Foundation for Suicide Prevention College Screening Project at Emory University. Depress anxiety. 2008;25(6):482-488.

10. Pitpitan EV, Kalichman SC, Eaton LA et al. Gender-based violence and HIV sexual risk behavior: alcohol use and mental health problems as mediators among women in drinking venues, Cape Town. Soc Sci Med. 2012;75(8):1417-1425.

11. Nduna M, Rachel K Jewkes, Kristin L Dunkle et al. Associations between depressive symptoms, sexual behaviour and relationship characteristics: a prospective cohort study of young women and men in the Eastern Cape, South Africa. J Int AIDS Soc. 2010;13(1):44.

12. Vitaliano PP, Russo J, Carr JE, Heerwagen JH Medical school pressures and their relationship to anxiety. The Journal of nervous and mental disease. 1984;172(12):730-736.

13. Connor-Smith JK, Compas BE, Wadsworth ME et al. Responses to stress in adolescence: measurement of coping and involuntary stress responses. Journal of consulting and clinical psychology. 2000;68(6):976-972.

14. Winter Y, Alexei Korchounov, Tatyana V Zhukova et al. Depression in elderly patients with Alzheimer dementia or vascular dementia and its influence on their quality of life. Journal of neurosciences in rural practice. 2011;2(1):27-32.

15. Springer DW, Rubin A, Beevers CG Treatment of depression in adolescents and adults: Clinician's guide to evidence-based practice. 4. 2011

16. Lim LL, Weining C, Xin Yu et al. Depression in Chinese elderly populations. Asia-Pacific Psychiatry. 2011;3(2):46-53.

17. Gladstone TR, Beardslee WR, and O'Connor EE The prevention of adolescent depression. Psychiatric Clinics of North America. 2011;34(1):35-52.

18. McKenzie M, Olsson CA, Jorm AF et al. Association of adolescent symptoms of depression and anxiety with daily smoking and nicotine dependence in young adulthood: findings from a 10-year longitudinal study. Addiction. 2010;105(9):1652-1659.

19. Ceyhan A, Ceyhan E, Kurtyilmaz Y Investigation of university students depression. Eurasian Journal of Educational Research. 2009;36:75-90.

20. Supe AN A study of stress in medical students at Seth GS Medical College. Journal of postgraduate medicine. 1998;44(1):1-6.

21. Saipanish R Stress among medical students in a Thai medical school. Medical teacher. 2003;25(5):502-506.

22. Sherina M, Rampal L, Kaneson N Psychological stress among undergraduate medical students. Medical Journal of Malaysia. 2004;59(2):207-211.

23. Shaikh BT, Kahloon A, Kazmi M et al. Students, stress and coping strategies: a case of Pakistani medical school. Educ Health. 2004;17(3):346-353.

24. Yasmin R, Sidra Sohail Asim, Huma Ali et al. Prevalence of Perceived Stress among Pharmacy students in Pakistan. 2013

25. Kasi PM, Haider Ali Naqvi, Abaseen Khan Afghan et al. Coping styles in patients with anxiety and depression. ISRN psychiatry. 2012. 